\title{
TRAJETÓRIA DE CRESCIMENTO DA ECONOMIA BRASILEIRA E MUDANÇA ESTRUTURAL DE 1971 A 2008: UMA INTERPRETAÇÃO A PARTIR DO FRAMEWORK SPACE*
}

\section{Marcos Tostes Lamonica ${ }^{1}$ \\ Carmem Aparecida Feijó ${ }^{2}$ Lionello F. Punzo ${ }^{3}$}

RESUMO: O objetivo do texto é analisar a trajetória de crescimento da economia brasileira dos anos de 1970 até 2008, considerando as flutuações do investimento e da produtividade como determinantes do comportamento dessa trajetória. Assim, identificamos e qualificamos diferentes fases ou caminhos de crescimento compondo a trajetória de longo prazo. O comportamento oscilatório dessa trajetória tem sido atribuído a conjecturas de várias naturezas; aqui enfatizaremos as mudanças nas políticas econômicas e seus efeitos sobre a estrutura produtiva via mudança estrutural induzida que repercute na dinâmica observada. Apoiados na visão kaldoriana e neo-schumpeteriana introduziremos o Framework Space como instrumento de análise da dinâmica da trajetória de crescimento econômico do Brasil.

PALAVRAS-CHAVE: Crescimento econômico; mudança estrutural; investimento; produtividade.

CLASSIFICAÇÃO JEL: O11; O14.

*Artigo recebido em 02/09/2010 e aprovado em 20/04/2012.

${ }^{1}$ Doutor em Economia pela Universidade Federal Fluminense e professor adjunto do Departamento de Economia da Universidade Federal Fluminense. Contato: marcostostes@hotmail.com.

${ }^{2}$ Doutora em Economia pela University College London e professora associada do Departamento de Economia da Universidade Federal Fluminense. Contato: cfeijo@terra.com.br.

${ }^{3}$ Professor titular de Economia e lecturer em Economia do Turismo Sustentável da Facoltá di Economia

"Richard Goodwin". Contato: punzo@unisi.it. 


\section{GROWTH CICLES AND STRUCTURAL CHANGE IN THE BRAZILIAN ECONOMY FROM 1971 TO 2008: AN INTERPRETATION USING THE FRAMEWORK SPACE ANALYTICAL DEVICE}

ABSTRACT: The aim of the text is to analyze the growth pattern of Brazilian economy from 1970 to 2008, regarding the fluctuations in investment and the productivity as characterizing this trajectory. We thus identify and qualify different growth phases. The resulting overall trajectory oscillatory behavior has being attributed to conjectures of many natures. Herein we will focus, on the change in economy policies and their effects on the productive structure via the induced structural change that reverberates into observed dynamics, the just mentioned phases of the growth oscillation. We are suppored by Kaldorian and neo-Schumpeterian view and resort to the Framework Space as the method to analyze the dynamic feature of fluctuating economic growth in Brazil.

KEYWORDS: Economic growth; structural change; investment; productivity. 


\section{INTRODUÇÃO}

Trajetórias de crescimento de economias em desenvolvimento são em geral restringidas por problemas de balanço de pagamentos. Esse foi o caso da economia brasileira no início dos anos 1960 e novamente no início dos anos 1980 e, mais recentemente, na segunda metade dos anos 1990 com a sequência de crises financeiras como a do México, em 1995, da Ásia em 1997 e da Rússia em 1998. A superação dos problemas externos implica mudanças na estrutura do funcionamento da economia e de acordo com a direção das mudanças, novos desafios serão colocados influindo na trajetória de crescimento futura. As diversas teorias do crescimento buscam explicar de forma concorrente como se desenvolvem as trajetórias.

A teoria neoclássica, assim como mais recentemente as novas teorias do crescimento endógeno, aponta a restrição pelo lado da oferta como os responsáveis para a desaceleração ou aceleração no ritmo de crescimento das economias. As restrições de demanda, tanto interna quanto externa, não fazem parte do aparato analítico que explicam as trajetórias de crescimento. O diagnóstico neoclássico, ou convencional, para explicar a dinâmica do crescimento parte de uma construção teórica baseada na análise de funções de produção agregadas e na desagregação do crescimento em termos do crescimento dos fatores de produção e de suas produtividades. Assim, diferenças no ritmo de crescimento do produto entre países ou entre períodos diferentes em um mesmo país ou região podem ser explicadas em termos de taxas de crescimento do fator trabalho, da acumulação de capital e do progresso técnico e de suas respectivas produtividades.

Thirlwall (2003, p. 47) observa que essa abordagem, embora muito versátil por permitir a inserção de outras variáveis na função de produção que possam gerar resultados empíricos interessantes, não responde a uma questão fundamental: por que a oferta de fatores e a produtividade crescem a taxas diferentes entre países. Segundo ele, é porque a teoria neoclássica trata a oferta de fatores e o progresso técnico como variáveis exógenas ${ }^{4}$. Argumenta ainda que em termos práticos, observa-se que o crescimento da força de trabalho, da acumulação de capital e do progresso técnico, em grande medida, dependem da força da demanda agregada. Acrescentamos a essa visão o fato de que a força da demanda agregada, por sua vez, depende entre outras coisas, da gestão da política econômica no curto prazo $^{5}$. Assim, a abordagem e modelos de

\footnotetext{
${ }^{4}$ Segundo Thirlwall (op. cit., p. 49) a hipótese de Kaldor de progresso técnico incorporado é suficiente para substituir a função de produção neoclássica, e explicar porque rendimentos de escala são crescentes em determinados setores da economia.

${ }^{5}$ Ver Libânio (2009), para uma discussão sobre o crescimento sendo explicado pela demanda agregada.
} 
crescimento com ênfase na demanda permitem identificar uma interação interessante entre eventos históricos de curto prazo com trajetórias de crescimento de longo prazo.

Nosso objetivo neste texto é identificar fases componentes da trajetória de crescimento da economia brasileira nas últimas quase 4 décadas começando em 1971, levando em consideração o papel da demanda agregada como seu determinante. Nossa hipótese de trabalho é que a política econômica exerce papel importante no processo de crescimento, assim influindo na trajetória de longo prazo. A interação entre a dinâmica de curto e a de longo prazo geraria uma trajetória de crescimento não linear, que não tende para uma posição de equilíbrio pré-determinada (como previsto na abordagem da teoria convencional). Essa hipótese inicial nos leva a considerar que mudanças descontínuas na trajetória de crescimento, que refletem e têm impacto sobre a estrutura produtiva, provocam mudanças estruturais. Dessa forma, nosso entendimento sobre a dinâmica de crescimento de uma economia associa sua trajetória de crescimento com mudança na estrutura produtiva que, por sua vez, condiciona qualitativamente a trajetória futura de crescimento. Este é o estudo de caso para o Brasil.

A economia brasileira experimentou crescimento acelerado do pós-guerra até 1980 (6,4\% crescimento médio ao ano). Esse crescimento foi interrompido com a crise da dívida externa em 1980-1981 que trouxe constrangimentos ao tipo de financiamento empregado pela política desenvolvimentista adotada até então. No início da década de 1980, a trajetória da taxa de crescimento seria interrompida por força da restrição externa, mas tão logo o problema externo foi equacionado pelo aumento das exportações, como ocorreu entre 1984-1985, taxas positivas e expressivas voltaram a ocorrer. Porém, a retomada da inflação viria a comprometer o crescimento no restante da década e, parafraseando Castro (2008), depois daquele momento heróico que se seguiu após a recessão do início da década, as taxas de crescimento beiraram a semiestagnação. Embora a inflação elevada tenha sido controlada em meados da década de 1990, as taxas de crescimento dos anos 1990 e 2000 foram bem inferiores às observadas nos anos 1970.

Nossa interpretação sobre as fases de crescimento econômico irá se apoiar nas visões kaldoriana e neo-schumpeteriana para qualificar as mudanças estruturais na economia brasileira, ou seja, as mudanças no que chamaremos de regime de crescimento. Partindo dessas premissas, nosso objetivo é analisar a trajetória de crescimento da economia brasileira a partir dos anos de 1970, considerando as flutuações do investimento e da produtividade como determinantes de diferentes regimes de acumulação de capital. Empregaremos a metodologia de análise desenvolvida nos 
trabalhos por Bohn e Punzo (2001) e Gaffard e Punzo (2005), e aplicada empiricamente em diversas economias ${ }^{6}$.

Além desta introdução, o texto apresenta mais duas seções e uma conclusão. $\mathrm{Na}$ segunda seção será introduzido o Framework Space, um método de análise da estrutura dinâmica, ou articulação em fases da trajetória de crescimento num espaço onde a teoria neoclássica ou convencional e a endógena podem ser interpretadas de forma consistente para explicar trajetórias específicas de crescimento. A terceira seção será reservada à aplicação desse instrumento ao caso brasileiro no intervalo 1971-2008; a evolução temporal dessa trajetória será traçada em três fases. Na quarta e última seção apresentamos algumas considerações finais.

\section{A METODOLOGIA DE ANÁLISE DO FRAMEWORK SPACE}

Para analisar a trajetória de crescimento da economia brasileira nas últimas quase quatro décadas iremos explorar o aparato analítico do Framework Space (FS), onde as mudanças estruturais são identificadas como mudanças de regime de crescimento. Essa ferramenta permite interpretar a trajetória de crescimento de uma economia ao longo do tempo como uma sucessão de múltiplos regimes, onde ora predomina a acumulação de capital propriamente dita, ora os ganhos de produtividade fruto da acumulação de capital em período anterior, ou resultante da introdução de inovações. Essa forma de interpretar a trajetória de crescimento se contrapõe à teoria do crescimento neoclássica, que supõe que a trajetória de crescimento da economia no longo prazo é do tipo estacionária, ou seja, a taxa de crescimento tem pouca ou nenhuma variação ao longo dos anos, mantendo uma trajetória de crescimento constante e permanecendo em um único tipo de regime ou padrão de crescimento. $\mathrm{Na}$ trajetória de steady state, a taxa de crescimento depende somente das taxas de crescimento populacional e da tecnologia.

De acordo com a teoria convencional as economias viajariam mais ou menos suavemente ao longo do tempo, podendo haver convergência entre as taxas de crescimento entre os países. Böhm e Punzo (2001) e Gaffard e Punzo (2005) consideram que a existência de uma única linha de raciocínio é insuficiente para explicar o comportamento da trajetória de crescimento das economias. Esses autores introduzem o FS, o qual apresenta um menu de modelos ou padrões de crescimento que podem ser

\footnotetext{
${ }^{6}$ A metodologia empírica denomina-se Framework Space (FS) e tem sido aplicado em vários países. Para uma aplicação no México, Estados Unidos e Itália 1970-1993 ver Anyul e Punzo (2001); Alemanha, França, Japão, USA, Itália 1970-1992 ver Böhm e Punzo (2001); România (1990-1997), Reino Unido (1973-1999) e Holanda (1987-2002) e outros países, ver Gaffard e Punzo (2005).
} 
utilizados para analisar e explicar as oscilações observadas na trajetória de crescimento ao longo do tempo como resultado também das mudanças estruturais que modelos tradicionais excluem.

A teoria do crescimento convencional considera taxas médias de crescimento de longo prazo como parâmetros da análise do desempenho econômico, porém, observa-se na prática que ao longo de um determinado período de tempo o mais provável de ocorrer é que o nível da taxa de crescimento flutue. Essas flutuações podem ser decorrentes da interação das inúmeras variáveis que explicam a atividade econômica. O Framework Space se propõe a explicar as flutuações que provocam mudanças estruturais - mudança de regime - na economia, e, portanto mudanças na trajetória de crescimento. Nesse contexto, a política econômica e os condicionantes internos e externos do mercado são apontados como decisivos para explicar porque as economias podem apresentar ao longo do tempo distintas trajetórias de crescimento. A contribuição do FS é no sentido de reconhecer a possibilidade de diferentes teorias de crescimento serem consistentes umas com as outras (Böhm e Punzo, 2001, p. 63). Essa estrutura analítica permite levar em conta a abordagem exógena encontrada no modelo de Solow (1956) e outras teorias de crescimento endógeno, inclusive a kaldoriana e a neo-schumpeteriana. Voltaremos a esse ponto.

Por outro lado, o FS é um instrumento criado para recolher um conjunto de eventos históricos e/ou fatos estilizados, tratados como cenários econômicos. Isso implica dizer que é possível identificar fases de crescimento que podem ser delimitadas por tais "cenários", onde o comportamento da trajetória de crescimento pode se mostrar bastante volátil. Uma trajetória então é definida como uma sequência ordenada de fases de crescimento.

Dessa forma, a dinâmica do FS pode ser tratada como um modelo heurístico empregado para classificar certos fenômenos empiricamente observáveis na economia. A interpretação das fases de crescimento, através do FS, identifica na trajetória de crescimento de longo prazo mudanças nos padrões de crescimento econômico com sua própria interpretação teórica. Essas interpretações incluem a teoria neoclássica, keynesiana e neo-schumpeteriana como casos referentes a episódios e/ou experiências especificas. A teoria neoclássica assume uma função de produção com progresso técnico e crescimento da população ambos exógenos. A visão da tradição keynesiana/ kaldoriana supõe o progresso técnico incorporado, o investimento como o veículo 7 . Então, a produtividade aumentará quanto mais acelerado o processo de acumulação de capital. A dinâmica de acordo com a linha neo-schumpeteriana explica o crescimento

${ }^{7}$ Ver Kaldor (1957) e Kaldor-Mirrlees (1961-1962). 
pelo ritmo de inovações, das novas formas de organizar a produção e a distribuição de novos produtos que aumentam o gap entre o custo unitários e o preço final para venda.

Böhm e Punzo (2001, p. 48), assumindo o leque de interpretações acima, especificam as variáveis da trajetória dinâmica em termos de taxas ao invés de níveis. No aparato do FS trabalha-se com duas variáveis estado: Investimento por Emprego e Produtividade (produto por emprego), com o objetivo de explicar a relação da dinâmica da flutuação na produtividade vis-à-vis dinâmica da flutuação do investimento (por emprego).

Nesse sentido, o aparato analítico do FS permite explicar i) por que um país pode apresentar ao longo do tempo diferentes níveis de taxas de crescimento econômico e também ii) por que as trajetórias de crescimento variam entre países. Assim através das diferentes abordagens do crescimento (em função do progresso técnico exógeno, da acumulação de capital e da inovação), o FS torna-se um instrumento para auxiliar a explicação da variedade temporal e geográfica/setorial da experiência do crescimento ${ }^{8}$.

A construção do Framework Space inicia-se tomando as séries do PIB ou valor adicionado $(v a)$ e da formação bruta de capital fixo $(i)$ em termos reais, e do emprego (e). Assim define-se:

$$
\begin{gathered}
d \frac{d(\log v a-\log e)}{d t}=g v \\
\frac{d(\log i-\log e)}{d t}=g i
\end{gathered}
$$

Onde $g v$ é a taxa de crescimento do produto por emprego (uma medida da taxa de crescimento da produtividade) e gi é a taxa de crescimento do investimento por emprego. As variáveis $g v$ e $g i$ fornecem as coordenadas da trajetória dinâmica de uma determinada economia no plano (Figura 1). Alterações nos níveis das coordenadas $(g v, g i)$ representam mudanças na relação dinâmica da economia analisada, podendo configurar ou alterações na intensidade das variáveis ou mudanças de regime, ie, mudança estrutural ${ }^{9}$.

\footnotetext{
${ }^{8}$ Para uma discussão sobre modelos dinâmicos com múltiplos regimes, ver, por exemplo, Brida e Punzo (2003).

${ }^{9}$ A mudança estrutural tem uma interpretação diferente em outras abordagens. Ela pode ocorrer quando há alterações na composição do PIB ou dos agregados econômicos, ou quando ocorre mudança na estrutura organizacional e institucional de uma economia. Na visão de Kaldor, mudança estrutural é observada quando há alterações na composição da indústria de transformação com relação a intensidade tecnológica. Estas seriam captadas pelas elasticidades da demanda por exportação e importação. Desse modo, de acordo com o modelo Kaldor-Thirlwall, uma mudança estrutural poderia estar agindo a favor ou contra o crescimento da economia com equilíbrio no balanço de pagamentos. Ver Dixon e Thirlwall (1982), Thilwall (1979) e New Palgrave (1994).
} 
A Figura 1 ilustra como interpretar as trajetórias de crescimento e suas fases no aparato do FS. Nessa estrutura são tratados seis regimes e mais um regime especial. Esse último é o espaço tangente à linha que corta o plano das coordenadas ( $g v$, gi) no ângulo de $45^{\circ}$; é o chamado corredor harrodiano ${ }^{10}$ que separa o regime IV acima da linha, do regime I abaixo da linha. Ambos os regimes VI (Acumulação) e I (Inovação) estão no primeiro quadrante onde ocorre o crescimento econômico, isto é, onde as taxas de crescimento da produtividade $(g v)$ e do investimento por emprego (gi) são positivas. O regime II (Reestruturação), no segundo quadrante, combina um gv positivo e um gi negativo. Os demais regimes, III, IV e V são, na estrutura analítica do FS, tratados como reflexos dos regimes citados acima. São os regimes duais.

Esses regimes espelhos têm o comportamento em termos de taxas de crescimento inverso ao aos regimes VI, I e II. No regime III e IV as taxas de crescimento de $g v$ e $g i$ são ambas negativas, ficando no terceiro quadrante (o quadrante da retração econômica). No quarto e último quadrante, que coincide com o regime onde o gv é decrescente e o gi crescente, descreve uma situação na qual o crescimento da intensidade do investimento em capital por emprego não resulta em um incremento do produto por trabalhador. Essa situação é o contrário de qualquer predição das variadas teorias do crescimento.

FIGURA 1 - O FRAMEWORK SPACE

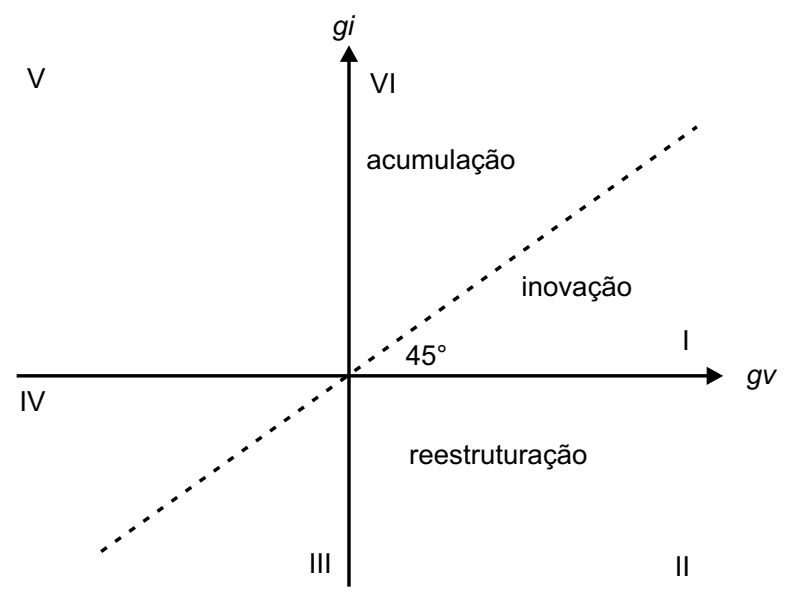

${ }^{10} \mathrm{O}$ comportamento harrodiano é tipicamente representado pela trajetória de steady state. As coordenadas $(0,0)$ se associam ao caminho de crescimento exógeno (Böhm e Punzo, 2001, p. 53). 
A interpretação relevante para nossa argumentação é que o FS é dotado de três padrões ou regimes de crescimento: i) steady state; ii) acumulação, focando as mudanças na intensidade do investimento, e; iii) a inovação, funcionalmente independe da acumulação de capital. A trajetória de crescimento é traçada pela sequência formada em função dos pares de $g v$ e gi, distribuídos no plano do FS. Cada ponto no FS, o par dessas coordenadas, está associado a uma trajetória de crescimento.

Para formalizarmos a interpretação das trajetórias no FS, partimos da teoria de crescimento neoclássica a qual supõe que a predição do comportamento de longo prazo da economia, sob certas condições está baseada nas propriedades de uma função de produção. A partir da função de produção mais uma equação de acumulação de capital pode-se encontrar um valor constante para a taxa de crescimento do produto per capita, comumente conhecida como a taxa de crescimento de steady state. Essa taxa é encontrada quando a taxa de investimento per capita requerido (necessário para manter a relação capital-trabalho constante) iguala-se ao investimento per capita efetivo, ou seja, é a condição de equilíbrio do modelo de Solow. Podemos definir que a teoria neoclássica assume uma taxa de crescimento $g_{N C}$, de steady state, dada por:

$$
g_{N C}=n+\lambda
$$

Considera-se $n$, a taxa de crescimento da população, como exógena, assim como a taxa de crescimento do progresso técnico $\lambda$. No entanto, a taxa de crescimento observada das economias é diferente da exógena ${ }^{11}$. Esta diferença é o que se pretende explicar com o auxílio do FS. Assim, o FS tenta explicar a taxa endógena de crescimento $g_{E N}$ dada por desvios da taxa observada $g$ da taxa de crescimento de steady state.

$$
g_{E N}=g-(n+\lambda)
$$

O FS irá considerar a taxa $g_{N C}$ como ponto de origem do diagrama da Figura 1, as coordenadas $(0,0)$, e dessa forma definimos aquilo que é relevante para ser investigado, isto é, a análise da taxa de crescimento endógena ${ }^{12}$. Nesse sentido, assumimos

\footnotetext{
${ }^{11}$ León-Ledesma e Thirlwall (2002) testaram para um conjunto de 15 países da OCDE a hipótese da endogeneidade da taxa natural de crescimento, assim como Libânio (2009) o fez para um grupo com as 12 maiores economias da América Latina, ambos tiveram êxito. A taxa natural de crescimento aumenta em períodos de expansão e reduz na contração porque a força de trabalho e o crescimento da produtividade são elásticos ao crescimento da demanda e do produto.

${ }^{12}$ Vale mencionar que Romer (1986), Lucas (1988), Romer (1990) entre outros, buscaram endogenizar a taxa de crescimento ao introduzir conhecimento, capital humano e novas idéias através de P\&D na estrutura da função de produção do modelo de Solow. Essa evolução da teoria neoclássica ficou conhecida como a "nova teoria do crescimento".
} 
que o comportamento da taxa efetiva $g$ influencia a trajetória de longo prazo e desse modo, assumimos que a taxa de crescimento endógena pode ser explicada através de dois regimes ou modelos de crescimento: o da acumulação de capital e o da inovação. Isso porque assumimos que tanto o ritmo de acumulação de capital com progresso técnico incorporado quanto o de inovação na economia influenciariam a taxa de crescimento efetiva, consequentemente, a sua trajetória ao longo do tempo.

No espaço bidimensional do FS, todas as teorias de longo prazo estão presentes. O modelo de Solow (1957) está na origem ${ }^{13}$, os pontos observados fora da origem indicam crescimento endógeno que pode ser explicado tanto pela teoria kaldoriana, regime de acumulação de capital, quanto pela teoria neo-schumpeteriana, regime de inovação. Nesse sentido, a elucidação de um crescimento exógeno ou endógeno pode utilizar duas classes de modelos (convencional e o kaldoriano e neo-schumpeteriano, os últimos endógenos) que estudam a dinâmica de longo prazo $^{14}$.

\section{UMA APLICAÇÃO DO FS À ECONOMIA BRASILEIRA DE 1971-2008}

A aplicação do FS no período 1971-2008 permitiu compartimentar a trajetória de crescimento em três fases ${ }^{15}$. Cada fase está representada nas Figuras de 2 a 4 .

\section{DELIMITANDO AS FASES DE CRESCIMENTO SEGUNDO EVENTOS HISTÓRICOS}

Elegemos três fases (ou ciclos) que nos mostram como as flutuações da trajetória de crescimento de 1971-2008 compõem comportamentos cíclicos diferentes ${ }^{16}$. Assumimos que o contexto macroeconômico experimentado pela economia em cada fase analisada contribuiu para construir a trajetória de crescimento. Desse modo o FS é aplicado contra um conjunto de cenários econômicos já ocorridos e debatido na literatura.

\footnotetext{
${ }^{13}$ Como a teoria neoclássica associa cada valor de $g_{N C}$ a uma trajetória de crescimento, quando $\lambda=0$ e $n=0$ o valor de $g_{N C}$ no steady state no longo prazo permanece na origem do eixo da abscissa.

${ }^{14}$ Vale lembrar que modelos endógenos com ênfase em situações de desequilíbrio se inspiram nas contribuições, dentre outros, de Richard Goodwin. Ver Punzo, 2006.

${ }^{15}$ Conforme disponibilidade dos dados foram utilizadas as seguintes séries estatísticas para derivar as taxas gv e gi: PIB da Indústria de Transformação conforme as Contas Nacionais; Emprego da Indústria de transformação de acordo com a Pesquisa Industrial Mensal do IBGE, e para o ano de 2001 o dado foi encontrado no MDICT e Estoque Líquido de Capital, série revista, segundo Morandi e Reis, disponível no IPEADATA. ${ }^{16} \mathrm{Na}$ periodização testada neste artigo são apenas três cenários/fases possíveis (ver, por exemplo, Bacha e Bonelli, 2005). Outras periodizações podem ser levadas em conta, alterando a trajetória. O que dá rigor à periodização é a análise dos eventos históricos relevantes.
} 
Na primeira fase (1971-81) o cenário é de crescimento acelerado e liquidez internacional, ocorrendo forte expansão do estoque de capital seguido pelo aumento da produtividade. Também foi um momento em que a taxa de investimento da economia brasileira persistiu num patamar acima dos $20 \%$. Essa fase descreve o período de maior crescimento do PIB, assunto amplamente debatido e aceito na literatura. $\mathrm{O}$ PIB cresceu em média a 7,4\% aa e a indústria de transformação a $7 \%$ a.a. ${ }^{17}$.

Na segunda fase (1981-1994) ocorre uma combinação de crise da dívida externa, devido à contração na liquidez internacional, acompanhado de um longo período de inflação alta. É um momento em que o cenário econômico internacional muda dramaticamente desfavorecendo economias em desenvolvimento com elevado grau de endividamento. Nesse período a economia sofreu duas recessões, 1982-1983 e 1990-1991 com expansão em 1984-1986 devido ao aumento das exportações, fruto do amadurecimento dos grandes projetos de investimento do II PND (Castro e Souza, 2004). O período 1981-1994 configurou no geral um quadro de desaceleração do ritmo de crescimento, com uma taxa média de crescimento anual de $2,3 \%$ a.a. e $1,5 \%$ a.a. para o PIB e indústria de transformação, respectivamente. Observa-se uma queda marcante no nível do emprego enquanto o investimento se mantém ainda em patamar relativamente elevado, ainda que menor que na década de 1970.

A terceira fase compreende o período entre 1994 a 2008. O quadro macroeconômico é de estabilidade monetária, e o início da década marcado pela abertura comercial que expôs o país a um choque tecnológico, resultando na recuperação do crescimento da produtividade.

O cenário externo, porém, combina deterioração do balanço de pagamentos, nos anos 1990, e sensível melhora a partir de 2003 com o crescimento dos preços das commodities exportadas pelo Brasil. A crise financeira internacional em setembro de 2008 interrompe momentaneamente a trajetória de crescimento, encerrando a última fase de nosso estudo.

Ao longo de todo o período nessa última fase observou-se uma política monetária de juros reais elevados e sobrevalorização cambial, o que criou um ambiente adverso para aqueles setores que dependem de volumosos investimentos para manterem-se competitivos. Ainda assim, a trajetória de crescimento se manteve, mas em ritmo

\footnotetext{
${ }^{17}$ A inclusão do ano de 1981 neste cenário, quando a inflação alcança a casa dos três dígitos, reduz as respectivas taxas médias em torno de $1 \%$.
} 
lento ${ }^{18}$, pois o dinamismo da indústria foi relativamente baixo (Feijó, Carvalho e Almeida, 2005). Com a valorização do câmbio 1995-1998, depois desvalorização 1999-2002 e novamente a valorização cambial a partir de 2003, a indústria sustentou seu crescimento via, basicamente, atividades inovadoras.

Em suma, delimitamos as fases considerando que a gestão da política econômica, juntamente com fatores externos, exerce influência decisiva na trajetória de crescimento econômico. Seus efeitos alteram as expectativas dos agentes causando flutuações no investimento em ativos fixos, com consequências para o crescimento futuro da economia. Nesse suposto, a política econômica pode ter tanto efeitos positivos, propiciando um maior crescimento, quanto negativos, induzindo a uma trajetória de crescimento mais lenta. Assim, políticas inadequadas ou mal administradas podem levar a uma obsolescência tecnológica e ou sucateamento da planta industrial com aumento do desemprego.

\section{FASE I: CRESCIMENTO ACELERADO - 1971-1981 - O CICLO MENOR ${ }^{19}$}

A fase inicial compreendeu I e II Plano Nacional de Desenvolvimento, configurando uma estratégia de política econômica tipicamente desenvolvimentista, privilegiando inicialmente os setores de bens duráveis e posteriormente os setores de bens de capital e intermediário e infraestrutura. É uma fase com intensa mudança na estrutura de produção da indústria de transformação.

Pela abordagem do FS, o início dos anos de 1970 é marcado por uma mudança estrutural através do aprofundamento da acumulação de capital, com o que resultou em uma mudança da composição do produto. Pela Figura 2 vemos a mudança ocorrendo de um regime de inovação começando em 1972 e 1973 para o de acumulação com aumento da produtividade. $\mathrm{O}$ crescimento da produtividade no regime orientado por atividades inovadoras se dá num ambiente de baixo investimento em capital, consistente com o período do I PND em que o crescimento tanto do produto agregado quanto da produtividade ocorreu através da redução da ociosidade e melhor utilização da capacidade produtiva. Ao se esgotar a ociosidade da indústria, uma

\footnotetext{
${ }^{18}$ Castro (2005) destaca uma fase o qual compreenderia o segundo semestre de 1994, quando a inflação "derrotada" e o primeiro semestre de 1999 devido a dois eventos, um no início e outro no final do semestre, a saber: a mudança do regime cambial, para o flutuante e a instalação do regime de Metas de Inflação pelo Banco Central (BC). Neste período, a política de juros altos, levado a cabo pelo BC, teria provocado um aumento expressivo da dívida pública doméstica e apreciação cambial. Se um restringia o investimento o outro impedia o crescimento das exportações, não menos importante, a redução do crédito internacional na ocasião das crises da Ásia e da Rússia expôs a política econômica adotada sua fragilidade quanto a viabilização de um crescimento firme e sustentável da economia brasileira.

${ }^{19}$ Classifica-se de menor um ciclo no interior de um regime, que não tem mudança estrutural.
} 
nova política econômica de cunho desenvolvimentista, marcada pelo II PND, seria voltada para a ampliação do produto potencial.

O resultado do Framework Space é bastante satisfatório para o período analisado, pois a taxa de crescimento da produção industrial, do emprego e, consequentemente, da produtividade moviam-se conjuntamente (Feijó e Carvalho, 2002).

FIGURA 2 - FASE DE CRESCIMENTO COM UM CICLO MENOR, 1971-1981

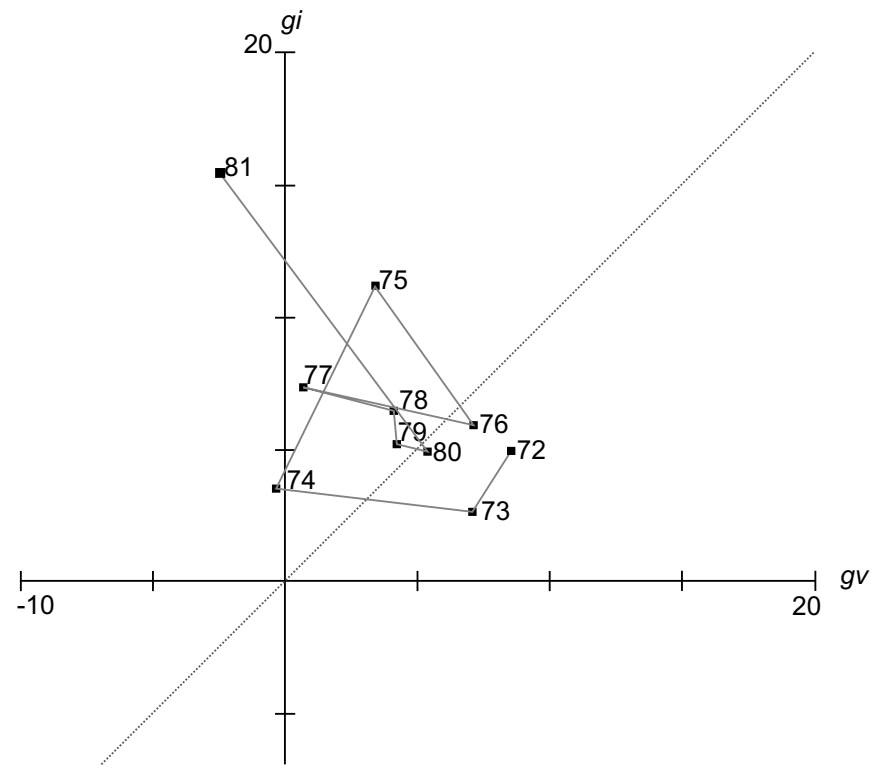

Fonte: Elaboração própria. Ver nota 15.

FASE II: DESACELERAÇÃO DO CRESCIMENTO 1982-1994 O CICLO MAIOR

Nesse período a aceleração da inflação e as dificuldades externas, ocasionadas pela crise da dívida externa no início da década, impediram a economia de continuar sua trajetória de crescimento puxado pela expansão da demanda como na fase anterior. As taxas de investimento caíram, assim como o crescimento do PIB e do emprego, e a produtividade ficou praticamente estagnada. No início dos anos 1990 ocorreu um amplo processo de reestruturação produtiva na indústria brasileira em função da abertura econômica. A indústria brasileira seria inserida num ambiente mais competitivo.

O comportamento da economia entre 1982 e 1994 é bastante disperso no plano do FS. Entre 1987 e 1992 o padrão de crescimento foi orientado pela acumulação, mas em um nível inferior ao de 1971-1981. Vale observar que o ano de 1990 é uma exceção nesse conjunto, pois foi marcado pelo Plano Collor, que provocou grande retrocesso no nível de produto pelo brusco enxugamento da liquidez. Em 1984-1985 e 1993-1994 a 
trajetória de crescimento foi orientada pelas atividades inovadoras devido ao registro de aumento da produtividade sem registro no investimento em formação de capital. O ano de 1986 é um ano atípico. Embora o crescimento do PIB tivesse se mantido acelerado como em 1984 e 1985, em 1986 a taxa de crescimento do pessoal ocupado na indústria foi muito elevada, devido possivelmente ao efeito do Plano Cruzado, primeira tentativa de Plano heterodoxo para controlar a inflação. Entre 1993-1994 a economia já havia iniciado a abertura econômica e conseguido a estabilidade monetária. Assim, é provável que a concorrência internacional tenha induzido as empresas a inovarem para manterem ou aumentar seu market share. O modelo indica, especialmente, que para esses dois momentos, 1984-1985 e 1993-1994, a taxa de crescimento da produtividade seja maior que a taxa de crescimento do investimento.

Conforme a Figura 3, vários episódios de mudanças estruturais se configuraram na fase II. Essa começou ainda com a trajetória no regime de acumulação, remanescente da fase anterior, e em 1984 registra uma mudança para o regime de inovação ao qual retorna nos anos finais. $\mathrm{O}$ crescimento acelerado da economia brasileira no intervalo 1984-1986 mostrou-se insustentável devido à escalada da inflação a partir do fracasso do Plano Cruzado. A inflação se tornaria, a partir de então, um obstáculo para o crescimento econômico, só debelado a partir de 1994 com o Plano Real, e comprometendo os níveis de investimento produtivos na sequência dos anos.

A introdução exógena de inovações (possivelmente através da aberturada econômica) e de maior impacto tecnológico foi responsável pelo crescimento da produtividade industrial nos anos noventa. (Feijó e Carvalho, 2002, p. 69). O investimento baixo implicou na queda no nível de emprego industrial.

\section{FASE III: CRESCIMENTO INSTÁVEL COM ESTABILIDADE DE PREÇOS 1994-2008 - CICLO DE REESTRUTURAÇÃO PRODUTIVA}

A política econômica da fase III é caracterizada, pelo stop and go nos anos 1990, o que está bem claro na dispersão dos pontos na FS (Figura 4). Essa dispersão mostra uma trajetória de crescimento com ausência de crescimento sustentado. Observa-se que em 1995 o padrão de crescimento é liderado pelo aumento da produtividade, ainda sob o efeito da abertura comercial. De 1996 a 1999 ocorre uma mudança no regime de crescimento com a economia passando por uma reestruturação, com incidência de pontos no regime de acumulação. A reversão do fluxo de capitais internacionais pelas crises de liquidez internacionais que ocorreram (Ásia em 1997 e Rússia 1998) levaram o país a adotar políticas fiscais e monetárias contracionista utilizadas para defender o país da escassez de divisas (Barbosa Filho, 2001), provocando desse modo uma contração na trajetória de crescimento do produto, que se reflete no início dos anos 2000. 
FIGURA 3 - FASE DE CRESCIMENTO COM UM CICLO MAIOR, 1981-1994

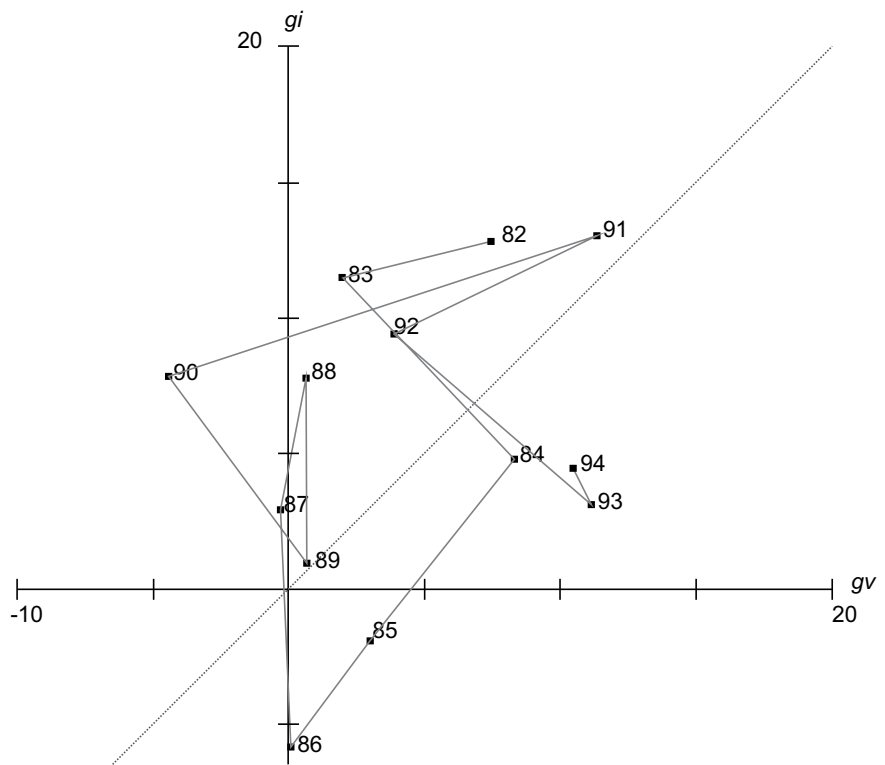

Fonte: Elaboração própria. Ver nota 15.

FIGURA 4 - FASE DE CRESCIMENTO COM ALTA INSTABILIDADE E REESTRUTURAÇÃO PRODUTIVA, 1994-2008

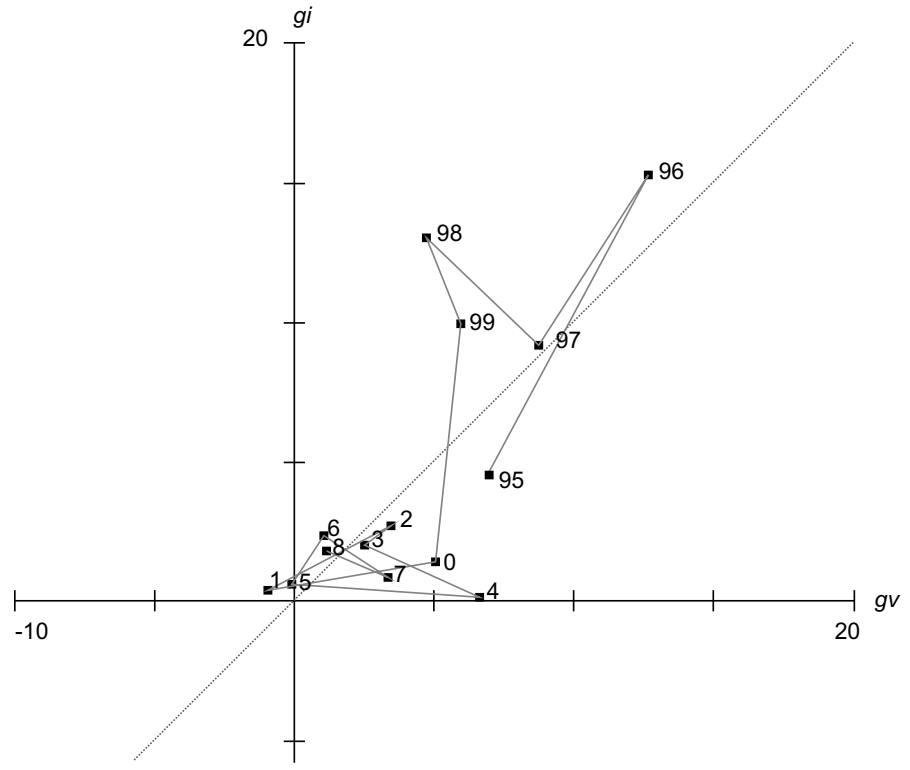


A partir de 1999 o padrão de crescimento alterna-se entre crescimento orientado pela acumulação de capital (2005-2006 e 2008) e crescimento induzido por uma dinâmica inovadora (2000, 2002-2004 e 2007). É bastante provável que a desvalorização cambial em 1999, tornando o investimento em máquinas e equipamentos importados e os financiamentos externos mais caros, tenha contribuído para as empresas tomarem uma estratégia defensiva dando continuidade ao processo de modernização dos processos produtivos com relativamente baixo desembolso para acumulação de capital. O racionamento de energia elétrica - apagão - em 2001 é outro fator que pesou nessa direção.

A partir de 2003 o aquecimento da demanda interna e da demanda externa pode ter alterado as expectativas dos empresários, no sentido de aumentar os incrementos na indústria, consequentemente no produto industrial. No entanto, o que se observa é que não há uma mudança estrutural clara no sentido de uma trajetória de crescimento liderada pela acumulação. Ainda predomina a alternância de pontos entre o espaço da inovação e da acumulação. Essa configuração ocorre em um cenário com crescimento das exportações e superávit nas Transações Correntes até a crise financeira internacional em 2008. A melhora dos termos de troca em função do aumento de preços das commodities que o país é grande exportador torna possível o aumento das exportações mesmo com a taxa de câmbio valorizada. No entanto, os condicionantes externos favoráveis não são suficientes para colocar o crescimento do produto agregado em ritmo acelerado. Tanto a política fiscal quanto a monetária são restritivas do ponto de vista da demanda agregada.

A característica do crescimento marcado pela inovação é o crescimento da produtividade, que ocorre a partir de 2003 de forma sustentada. Para Castro (2008), o aumento da capacidade de inovação surge como meio de competir no mercado externo em um ambiente de câmbio valorizado e taxa de juros (reais) doméstica elevada. A política de juros reais altos, a despeito do ambiente de estabilidade de preços, estaria sendo decisiva para o adiamento de um volume expressivo de investimento em máquinas e equipamentos de última geração ${ }^{20}$.

Uma consequência importante do baixo nível de investimento juntamente com a valorização da moeda doméstica por um longo período tem sido a perda de importância relativa da indústria de transformação no PIB. O argumento é que uma taxa de câmbio valorizada acaba penalizando a produção doméstica, especialmente o setor industrial. Isto pode ocorrer por duas formas: desestimulando as exportações e aumentando a importação na economia, principalmente de bens industrializados.

${ }^{20}$ Conforme Kaldor e Mirrlees (1961) isso aumenta a produtividade da indústria. A abordagem de Kaldor e Mirrlees apresenta o investimento em capital com uma forte relação com a produtividade. 
O processo de desindustrialização aparentemente já parece estar reduzindo o potencial de crescimento da economia brasileira, com a concentração de pontos próxima à origem no FS, além de tornar a economia mais vulnerável a choques externos no futuro, configurando trajetórias de crescimento mais modestas e mais instáveis.

\section{CONSIDERAÇÕES FINAIS}

O Framework Space mostrou-se um instrumento valioso na análise da trajetória da taxa de crescimento econômico. A dinâmica entre seus parâmetros produtividade e investimento por emprego permite inferir trajetórias de crescimento, que delineadas por fases ou cenários econômicos, mostram os diversos ciclos econômicos que ocorrem ao longo do tempo. O FS reforça o papel do investimento na teoria do crescimento, mostrando como seu perfil instável pode gerar flutuações na trajetória de crescimento das economias. Desse modo, a variação na intensidade dos parâmetros $(g i / g v)$ poderá mudar a tendência dessa trajetória, podendo provocar mudanças estruturais, ou seja, mudanças no regime de crescimento. Assim, dependendo do grau com que a política econômica influencia o ritmo de investimento e, por sua vez, o emprego pode influenciar a dinâmica da taxa de crescimento econômico, assim como o incentivo por parte do governo ao sistema de inovação.

A análise do comportamento da trajetória de crescimento brasileiro no período entre 1971-2008, a partir das relações dinâmicas entre investimento por emprego e produtividade, mostrou que o baixo desempenho do crescimento do PIB a partir dos anos 1980 pode ser explicado pela redução sistemática do investimento, especificamente, aqueles em máquinas e equipamentos mais avançados tecnologicamente. Por outro lado, a arrancada da produtividade dissociada de um crescimento robusto do investimento em capital não se mostrou capaz de levar a trajetória da taxa de crescimento do produto de volta à média histórica de 7,5\% ao ano. A inovação na indústria brasileira no período mais recente tem se mostrado uma prática defensiva à competição do que uma alternativa ao crescimento. Do mesmo modo que o Brasil não experimentou mais um aprofundamento do capital como na década de 1970, não experimentou também uma vigorosa taxa de crescimento como naquela época, sendo hoje a economia com menor crescimento frente às emergentes.

A persistência do último cenário aos dias de hoje, embora a existência de bases para um crescimento acelerado, não forma uma conjuntura apta a sustentar um crescimento vigoroso. O nível da taxa de juros (real) doméstica, a apreciação cambial acentuada e a insuficiência de investimentos, notadamente públicos em infraestrutura deprimem qualquer tentativa de uma alavancagem na atual taxa de investimento. Como efeito da política econômica, essas três variáveis têm influenciado a dinâmica da trajetória de crescimento e levado a mudanças estruturais, com perda precoce de importância no dinamismo da indústria para a liderança do crescimento. 


\section{REFERÊNCIAS}

ANYUL, M.P.; PUNZO, L.F. Structural Divergence and the Dynamics of Dualism: Lessons from Mexico before and after NAFTA. In . (eds.) Mexico beyond NAFTA: Perspectives for the European Debate. London: Routledge, 2001.

BACHA, E.; BONELLI, R. Uma interpretação das causas da desaceleração econômica do Brasil, Revista de Economia Política, v. 25, n. 3, p. 99, 2005.

BARBOSA FILHO, N. H. International Liquidity and Growth in Brazil, CEPA Working Paper, 2001.

BÖHM, B.; PUNZO, L.F. Productivity-Investment Fluctuations and Structural Change. In PUNZO, L.F. (ed.). Cycles, Growth and Structural Change: theories and empirical evidence. Londres: Routledge, 2001.

BRIDA, J.G.; PUNZO, L.F. Symbolic time series analysis and dynamics regimes, Structural Change and Economic Dynamics, v. 14, n. 2, 2003.

GAFFARD, J.L.; PUNZO, L.F. Economic Integration and Cross-country Convergence: exercises in growth theory and empirics. In FARINA, F.; SAVAGLIO, E. (eds.) Inequality and Economic Integration. London: Routledge. 2005.

CASTRO, A.B. A Hipótese de Crescimento Rápido e Sustentável. In VELlORSO, J.P.; ALBUQUERQUE, R.C. (orgs.) Cinco Décadas de Questão Social e os Grandes Desafios do Crescimento Sustentado. Rio de Janeiro: José Olympio Editora, 2005.

CASTRO, A.B. From Semi-stagnation to growth in a Sino-centric market, Revista de Economia Política, v. 28, n. 1, p. 109, 2008.

CASTRO, A.B.; SOUZA, F.P. A Economia Brasileira em Marcha Forçada. 3 ed. Rio de Janeiro: Editora Paz e Terra, 2004.

DIXON, R.; THIRLWALL, A.P. A Model of regional growth rate differences on Kaldorian lines, Oxford Economic Papers, v. 27, n. 2, 1975.

FEIJÓ, C.A.; CARVALHO, P.G.M. Uma Interpretação sobre a Evolução da Produtividade Industrial no Brasil nos Anos Noventa e as "Leis" de Kaldor, Nova Economia, v. 12, n. 2, 2002.

FEIJÓ, C.A; CARVALHO, P.G.M.; ALMEIDA, J.S.G. Ocorreu uma Desindustrialização no Brasil? São Paulo: IEDI, 2005, mimeo.

HARROD, R.F. An Essay in Dynamic Theory, Economic Journal, v. 49, n. 3, 1939.

KALDOR, N. A Model of Economic Growth, Economic Journal, 1957.

KALDOR, N.; MIRRLEES, J.A. A New Model of Economic Growth, Review of Economic Studies, v. 29, 1961-1962.

LEÓN-LEDESMA, M.A.; THIRLWALL, A.P. The Endogeneity of Natural Rate of Growth, Cambridge Journal of Economics, v. 26, 2002.

LIBÂNIO, G. Aggregate Demand and the Endogeneity of the Natural Rate of Growth: Evidence from Latin American Economies, Cambridge Journal of Economics, v. 33, n. 5, 2009. 
LUCAS, R.E. On the Mechanics of Economic Development, Journal of Monetary Economics, v. 22, 1988.

NEW PALGRAVE, THE: A dictionary of economics. EATWELL, J; MILGATE, M; NESSMAN, P. (eds.) London: The MacMillan Press Limited, 1994.

OECD. Structural Adjustment and Economic Performance. Paris: Organization for Economic Cooperation and Development, 1987.

PUNZO, L.F. Towards a disequilibrium theory of structural dynamics: Goodwin's contributions, Structural Change and Economic Dynamics, v. 17, n. 4, 2006.

ROMER, P.M. Increasing Returns and Long-Run Growth, Journal of Political Economic, v. 94, 1986.

ROMER, P.M. Endogenous Technological Change, Journal of Political Economic, v. 98, 1990.

SOLOW, R.M. A Contribution to the Theory of Economic Growth, Quarterly Journal of Economics, v. 70, 1956.

SOLOW, R.M. Technical Change and the Aggregate Production Function, Review of Economic and Statistics, v. 39, 1957.

THIRLWALL, A.P. Trade, the Balance of Payments and Exchange Rate Policy in Developing Countries. Cheltenham: Edward Elgar, 2003.

THIRLWALL, A.P. The Balance of Payments Constraint as an Explanation of International Growth Rates. Banca Nazionale del Lavoro Quarterly Review, March, 1979. 